\title{
Peer-reviewed publications of physical therapy staff members affiliated with universities in Saudi Arabia from 2007 to 2017: bibliometric and content- analysis
}

\begin{abstract}
Objective: Review the publications (2007-2017) generated by physical therapy staff members' associated with Saudi Universities.

Methods: Following the identification of those universities offering Physical Therapy/Physiotherapy programmes, a PRISMA strategy was used to search for the peer-reviewed publications using four electronic database (Scopus; ScienceDirect; Web of Science; and Google Scholar). Full-length papers were included if they were generated by an affiliated staff member and published in English in peer-reviewed papers. The bibliometric characteristics of the journals were documented.

Results: A total of 1127 titles were generated by the 14 Physical Therapy programmes. Following screening, 245 were determined to meet the inclusion criteria and were retained for analysis. There has been a systematic increase in the number of publications over the study timeframe. The "Journal of Physical Therapy Science" was the most the frequently $(14.69 \%)$ recorded publication. Publications were recorded in 107 journals. The bibliometric characteristics varied considerably.

Conclusion: There was evidence of a systematic increase in research publications indicating a greater commitment to conducting research among physical/physiotherapy programmes in Saudi Arabia universities.
\end{abstract}

Keywords: physiotherapy, physical therapy, affiliation, author, rehabilitation

\section{Introduction}

The first Physical Therapy (Physiotherapy) course in the Kingdom of Saudi Arabia (SA) was established at the King Saud University in 1979. ${ }^{1,2}$ Currently, there are 14 universities in Saudi Arabia that provide undergraduate Physical Therapy education. The bachelor's programme in Physical Therapy in Saudi Arabia ranges between five and six years and includes a one-year clinical internship. A postgraduate programme in physiotherapy was first established in 2000 (King Saud University), thus providing the potential for advanced study and training opportunities.

Fundamental to the teaching of evidence-based Physical Therapy is the development of solid research foundation..$^{2,3-6}$ With the growth of the number of schools and the introduction of a postgraduate programme there is the expectation that there is the growth of a research culture to inform and support teaching and advance knowledge. ${ }^{2}$ This is in keeping with the development of Physical Therapy research in other countries such as United Arab Emirates, China, India, America, Europe. ${ }^{7-10}$ An integral aspect of understanding research outputs is the need to develop a rigorous and systematic approach. ${ }^{1,3,11}$ Such approaches have previously been used to analyse the literature in specific areas of Physical Therapy. ${ }^{12,13}$

The importance of research, in SA Universities, including that in Physical Therapy, has recently been reinforced by the release of a major strategy document (Saudi vision 2030) ${ }^{14}$ designed to map out the importance and expectations for research within the Kingdom of SA. In releasing this document on behalf of the government in [2016], the Deputy Crown Prince Mohammad bin Salman Al Saud
Volume 4 Issue I - 2019

\author{
Baraa H Alsulaimani,' John Sullivan, ${ }^{2}$ Parsath \\ Jayakaran ${ }^{3}$ \\ 'Master Candidate, Centre for Health, Activity and \\ Rehabilitation Research, University of Otago, New Zealand \\ 2Professor, Centre for Health, Activity and Rehabilitation \\ Research, University of Otago, New Zealand \\ ${ }^{3}$ Lecturer, Centre for Health, Activity and Rehabilitation \\ Research, University of Otago, New Zealand
}

\section{Correspondence: Baraa H Alsulaimani, Master Candidate, Centre for Health, Activity and Rehabilitation Research, University of Otago, Dunedin, New Zealand, Tel 00966544606|42,Email bhalsulemani@kau.edu.sa}

Received: January 24, 2019 | Published: February 01, 2019 and the Ministry of Education signalled the value of original research in building the nation. ${ }^{14}$ This vision has impacted on many different government's agencies to enhance both governmental and personal incomes and to reward the generation of research outputs. ${ }^{14}$ With the expected surge in outputs in response to the Saudi Vision 2030 it is important to understand the current and historical research productivity of Physical Therapy departments in SA universities. Therefore, the purpose of this study was to characterise the research publications associated with the Physical Therapy department/programme of universities in Saudi Arabia. A secondary objective was to understand the bibliometric characteristic of the journal the papers appeared in.

\section{Methods}

\section{Design}

This is a bibliometric and content-analysis study which adopted a systematic review design.

\section{Identification of physical therapy departments}

The search strategy to locate the publications included a twostep process. The first step identified all Saudi universities providing Physical Therapy education, via the Saudi Ministry of Education website ("List of Saudi Arabian universities") and the names of the departments, divisions and/or schools from the respective university websites noted.

\section{Database search}

The second step included systematic searches for peer-reviewed journal publications by the academic staff affiliated with the 
universities and/or Physical Therapy departments/programmes identified in the first step. The detailed search strategy is shown in Appendix 1. The search was executed on 13th of March 2017 in the following databases: Scopus; Science Direct; Web of Science; and Google Scholar. The search was restricted to the periods 2007-2017. The search terms used were: "Physiotherapy", "Physical therapy", "affiliation [name of the university]". For the Department/programme with names other than Physical/Physiotherapy (such as Rehabilitation Sciences), a separate search was conducted with the respective name of the department and names of the staff as identified on the university website. The search results were exported to EndNote version X8 for managing the retrieved publications.

\section{Inclusion and exclusion criteria}

This study included peer-reviewed journal articles published in the English language between 2007 and 2017. Those considered for inclusion were publications with one or more authors affiliated with the Physical Therapy department in at least one of the universities based in Saudi Arabia.

Non-peer reviewed journal publications and other publications such as books, conference abstracts, case reports, meetings, congresses, erratum, and letters were excluded from the study. Articles for which full-text publications were not accessible via the University of Otago Library database were also excluded from the study. Moreover, a large number of excluded publications were categorized under name of "other" and did not fit the inclusion criteria

\section{Study procedure}

The PRISMA Statement method was followed for the articles screening. ${ }^{15}$ All database search results were exported to EndNote programme and duplicates removed by EndNote automatic process. Additional duplicates not identified in the automatic process were manually screened $(\mathrm{ABH})$ and removed. Articles were excluded if they would not meet the inclusion criteria. Once a final number of articles was itemised, reference lists of articles were sorted in tables, and certain journals were analysed regarding the list of included articles.

\section{Data extraction and analysis}

The following key data were extracted: date of publication, journal of publication, and the name of the university. The journal metrics as available from external source/s were also determined. Each journal title was searched in the Journal Citation Reports (JCR-Web of Science Impact Factor); Scopus/SCImago (Citescore); and ResearchGate (RG Journal Impact). ${ }^{16,17}$ In addition, official journal webpages were also searched to obtain any other associated metrics.

\section{Results}

The following 14 universities of Saudi Arabia were identified from the Saudi Ministry of Education website as delivering Physical Therapy training programmes ("List of Saudi Arabian universities"). Jazan University, Jouf University; King Abdulaziz University (KAU); King Khalid University (KKU); King Saud University (KSU); Najran University; Princess Nora bint Abdulrahman University; Prince Sattam Bin Abdulaziz University; Qassim University (QU); Taibah University (TU); Taif University; Umm Al Qura University (UQ); University of Dammam; University of Hail. All universities had a department named as Physiotherapy or Physical Therapy except for King Saud University which was named as Rehabilitation Sciences department.

\section{Database search}

The electronic search on four databases identified a total of 1,127 articles. The results of the step-by-step screening process is as illustrated in Figure 1. After removal of duplicates, 802 titles and abstracts were screened with respect to the inclusion/exclusion criteria. Of these, 245 articles met the final inclusion criteria.

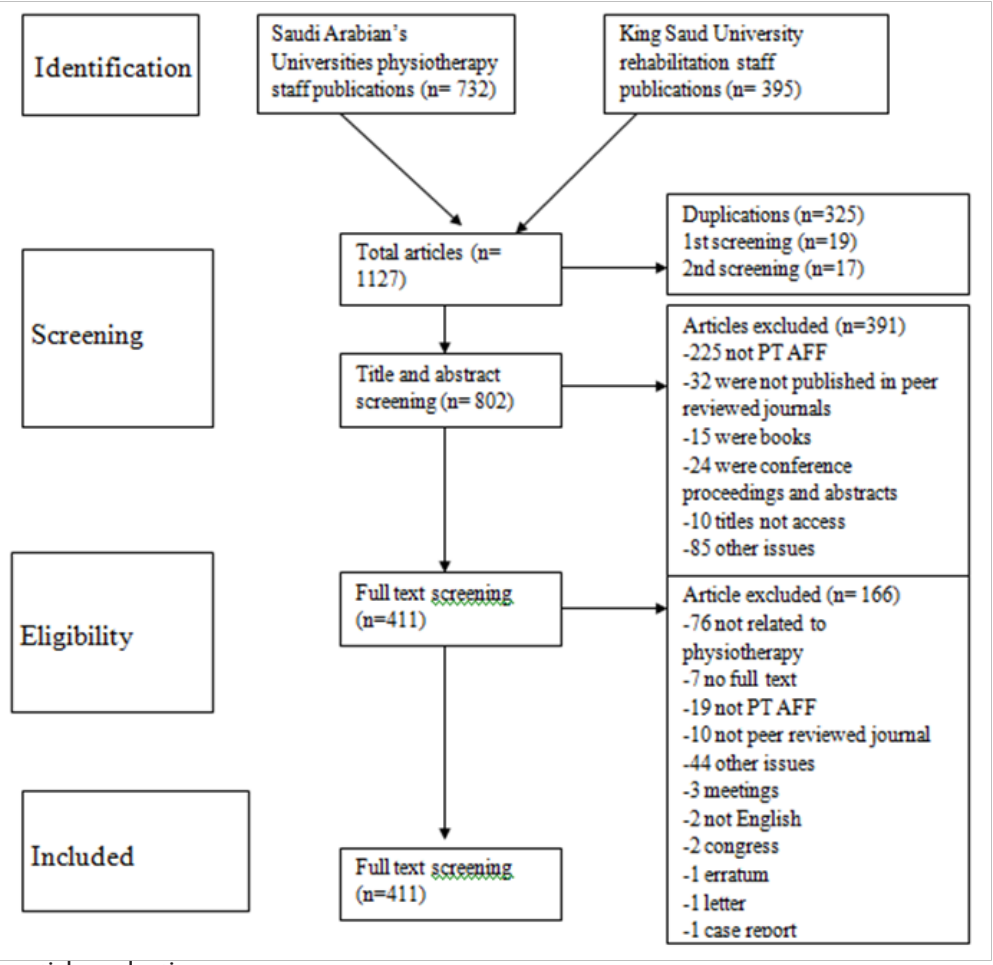

Figure I PRISMA flow chart of the articles selection process. 


\section{Content-analysis}

Appendix 2 presents the detailed demographic information of the 245 included articles. All these articles were published in 107 journals between 2007 and 2017.

A summary of the number of publications in each year from 2007 to 2017 is as shown in Figure 2. The search was conducted in March
2017 and only 8 articles had been published in 2017 to date. The number of publications has gradually increased over time from 2011 onwards. The maximum number of publications in any given year was 68 articles. The metrics of the 107 journals as extracted from an external source and the number of publications in each journal are detailed in Table 1.

Table I List of 107 journals, their metrics and number of publications in each journal

\begin{tabular}{|c|c|c|c|}
\hline & Journal & Journal metric* & Number of publications \\
\hline I & African Health Sciences & 0.642 (JCR) & 15 \\
\hline 2 & Alternative \& Integrative Medicine & 0.675 (web) & I \\
\hline 3 & American Journal of Medicine and Medical Sciences & I.195 (Google) & I \\
\hline 4 & American Journal of Physical Medicine and Rehabilitation & 2.064 (JCR) & 6 \\
\hline 5 & Archives of Dermatological Research & 2.146 (JCR) & 1 \\
\hline 6 & Archives of Physical Medicine and Rehabilitation & 3.045 (JCR) & 1 \\
\hline 7 & Asia Pacific Disability Rehabilitation Journal & 0.11 (Citescore) & 1 \\
\hline 8 & Asian Biomedicine & 0.134 (JCR) & 4 \\
\hline 9 & Asian Journal of Pharmaceutical and Clinical Research & 0.63 (Citescore) & I \\
\hline 10 & Asian Spine Journal & 0.97 (Citescore) & I \\
\hline 11 & Assistive Technology & 1.283 (JCR) & 1 \\
\hline 12 & Biological Trace Element Research & I.798 (JCR) & 1 \\
\hline 13 & BioMed Research International & 2.134 (JCR) & 2 \\
\hline 14 & Biomedical Research (India) & 0.226 (JCR) & 3 \\
\hline 15 & BMC Musculoskeletal Disorders & I.684 (JCR) & I \\
\hline 16 & Bone & 3.736 (JCR) & I \\
\hline 17 & Clinical Anatomy & 1.316 (JCR) & I \\
\hline 18 & Clinical Interventions in Aging & 2.133 (JCR) & 3 \\
\hline 19 & Clinical Journal of Pain & 2.712 (JCR) & I \\
\hline 20 & Clinical Rehabilitation & 2.403 (JCR) & 4 \\
\hline 21 & Current Opinion in Neurology & 4.469 (JCR) & I \\
\hline 22 & Der Pharma Chemica & 0.58 (Citescore) & 1 \\
\hline 23 & Diabetes Research and Clinical Practice & 3.045 (JCR) & 1 \\
\hline 24 & Disability and Rehabilitation & 1.919 (JCR) & 3 \\
\hline 25 & Ethiopian Journal of Health Sciences & 0.73 (Citescore) & I \\
\hline 26 & Ethnicity and Disease & 1.946 (JCR) & I \\
\hline 27 & European Journal of General Medicine & 0.10 (Citescore) & 6 \\
\hline 28 & European Scientific Journal & 0.654 (GIF) & I \\
\hline 29 & Foot \& ankle specialist & $0.80(\mathrm{RG})$ & I \\
\hline 30 & Functional Neurology & $\mathrm{I} .855$ (JCR) & I \\
\hline 31 & Health sciences & 0 & 2 \\
\hline 32 & Indian Journal of Physiotherapy and Occupational Therapy-An International Journal & 0.454 (GIF) & 2 \\
\hline 33 & Indian Journal of Dermatology & 0.74 (Citescore) & 2 \\
\hline 34 & Indian Journal of Rheumatology & 0.15 (Citescore) & 1 \\
\hline 35 & International Journal of Pharma and Bio Sciences & 0.35 (Citescore) & I \\
\hline
\end{tabular}


Table Continued...

\begin{tabular}{|c|c|c|c|}
\hline & Journal & Journal metric* & Number of publications \\
\hline 36 & International Journal of Physiotherapy Research & $0.16(R G)$ & 5 \\
\hline 37 & International Journal of Current Research and Review & 4.016 (web) & I \\
\hline 38 & International Journal of Diabetes in Developing Countries & 0.366 (JCR) & 1 \\
\hline 39 & International Journal of Environmental Research and Public Health & 2.035 (JCR) & I \\
\hline 40 & International Journal of Health Policy and Management & $\mathrm{I} .36$ (RG) & I \\
\hline 41 & International Journal of Health Sciences & $0.7 I$ (RG) & 2 \\
\hline 42 & International Journal of Innovation and Applied Studies & $0.45(\mathrm{RG})$ & I \\
\hline 43 & International Journal of Medical Research \& Health Sciences & 0.765 (GIF) & I \\
\hline 44 & International Journal of Medical Science and Public Health & 0 & I \\
\hline 45 & International Journal of Pharma and Bio Sciences & 0.35 (Citescore) & I \\
\hline 46 & International Journal of Pharmaceutical and Clinical Research & 0.18 (Citescore) & I \\
\hline 47 & International Journal of Rehabilitation Research & 1.250 (JCR) & 3 \\
\hline 48 & International Journal of Research in Medical Sciences & $0.90(\mathrm{RG})$ & I \\
\hline 49 & International Journal of Therapies and Rehabilitation Research & $0.37(\mathrm{RG})$ & 3 \\
\hline 50 & International Journal of Therapy and Rehabilitation & 0.19 (Citescore) & 2 \\
\hline 51 & International Wound Journal & 2.594 (JCR) & 1 \\
\hline 52 & Journal of American Science & 0.675 (GIF) & I \\
\hline 53 & Journal of Aging and Health & 1.660 (JCR) & 1 \\
\hline 54 & Journal of Back and Musculoskeletal Rehabilitation & 0.956 (JCR) & 5 \\
\hline 55 & Journal of Cardiovascular Disease Research & I.04 (Citescore) & 1 \\
\hline 56 & Journal of Clinical Densitometry & 2.644 (JCR) & 1 \\
\hline 57 & Journal of Clinical Epidemiology & 4.703 (JCR) & I \\
\hline 58 & Journal of Geriatric Physical Therapy & I.833 (JCR) & I \\
\hline 59 & Journal of Health Sciences & $\mathrm{I} .08$ (RG) & I \\
\hline 60 & Journal of Lasers in Medical Sciences & 0.60 (Citescore) & I \\
\hline 61 & Journal of Manipulative and Physiological Therapeutics & 1.329 (JCR) & I \\
\hline 62 & Journal of Mechanics in Medicine and Biology & 0.797 (JCR) & I \\
\hline 63 & Journal of Musculoskeletal Research & 0.18 (Citescore) & 4 \\
\hline 64 & Journal of Neurologic Physical Therapy & I.805 (JCR) & I \\
\hline 65 & Journal of Orthopaedic and Sports Physical Therapy & $2.55 \mathrm{I}(\mathrm{JCR})$ & 3 \\
\hline 66 & Journal of Pediatric Rehabilitation Medicine & 1.00 (Citescore) & I \\
\hline 67 & Journal of Physical Therapy Science & 0.392 (JCR) & 36 \\
\hline 68 & Journal of Stroke and Cerebrovascular Diseases & 1.599 (JCR) & I \\
\hline 69 & Journal of Taibah University Medical Sciences & 0.60 (Citescore) & 4 \\
\hline 70 & Journal of the American Geriatrics Society & 3.842 (JCR) & I \\
\hline 71 & Journal of the Chinese Medical Association & 1.013 (JCR) & I \\
\hline 72 & Journal of the Saudi Heart Association & 0.58 (Citescore) & 2 \\
\hline 73 & Journal of Vestibular Research-Equilibrium \& Orientation & I.047 (JCR) & 1 \\
\hline 74 & Lasers in Medical Science & $2.46 \mathrm{I}(\mathrm{JCR})$ & 6 \\
\hline 75 & Life Science Journal-Acta Zhengzhou University Overseas Edition & 0.165 (JCR) & 2 \\
\hline
\end{tabular}




\begin{tabular}{|c|c|c|c|}
\hline & Journal & Journal metric* & Number of publications \\
\hline 76 & Malaysian Journal of Medical Sciences & $0.73(\mathrm{RG})$ & 1 \\
\hline 77 & Medicine (United States) & 2.133 (website) & 2 \\
\hline 78 & Mediterranean Journal of Social Sciences & $0.26(R G)$ & 1 \\
\hline 79 & Medycyna Pracy & $0.40 \mathrm{I}(\mathrm{JCR})$ & 1 \\
\hline 80 & Middle-East Journal of Scientific Research & $0.36(R G)$ & 8 \\
\hline 81 & Neurology Research International & 2.80 (Citescore) & 1 \\
\hline 82 & NeuroRehabilitation & $\mathrm{I} .453$ (JCR) & 3 \\
\hline 83 & Neurosciences & $0.54 \mathrm{I}(\mathrm{JCR})$ & 2 \\
\hline 84 & Nitte University Journal of Health Science & 0.988 (GIF) & 1 \\
\hline 85 & Occupational Medicine \& Health Affairs & 0.465 (website) & 1 \\
\hline 86 & Open Access Library Journal & $0.13(\mathrm{RG})$ & 1 \\
\hline 87 & Open Journal of Internal Medicine & $0.12(R G)$ & 1 \\
\hline 88 & Oxidative Medicine and Cellular Longevity & 4.492 (JCR) & 1 \\
\hline 89 & Pakistan Journal of Medical Sciences & 0.544 (JCR) & 2 \\
\hline 90 & Pakistan Journal of Pharmaceutical Sciences & $0.58 \mathrm{I}(\mathrm{JCR})$ & 1 \\
\hline 91 & Parkinson's Disease & 1.722 (JCR) & 3 \\
\hline 92 & Pediatric Physical Therapy & I.IOI (JCR) & 1 \\
\hline 93 & Physikalische Medizin Rehabilitationsmedizin Kurortmedizin & 0.247 (JCR) & 6 \\
\hline 94 & Physiotherapy (United Kingdom) & $\mathrm{I} .814$ (JCR) & 4 \\
\hline 95 & Physiotherapy Theory and Practice & 1.169 (JCR) & 1 \\
\hline 96 & Rheumatology International & 1.702 (JCR) & 1 \\
\hline 97 & Saudi Medical Journal & 0.562 (JCR) & 4 \\
\hline 98 & Scientific World Journal & 1.219 (JCR) & 1 \\
\hline 99 & Somatosensory and Motor Research & 0.778 (JCR) & 5 \\
\hline 100 & Spine & 2.439 (JCR) & I \\
\hline 101 & Sports Medicine & 5.579 (JCR) & 2 \\
\hline 102 & Trends in Applied Sciences Research & 0.29 (RG) & 1 \\
\hline 103 & Trends in Medical Research & 0.38 (Citescore) & 1 \\
\hline 104 & Turkiye Fiziksel Tip ve Rehabilitasyon Dergisi & 0.094 (JCR) & 2 \\
\hline 105 & VirusDisease & 0.42 (Citescore) & 1 \\
\hline 106 & World Applied Sciences Journal & $0.47(\mathrm{RG})$ & 4 \\
\hline 107 & World Journal of Hepatology & 3.19 (Citescore) & 1 \\
\hline
\end{tabular}

*Journal Citation Reports (JCR) (Web of Science); Citescore (Scopus); Journal Impact (RG)

The highest number of publications $(\mathrm{n}=8$, and 15$)$ were in journals with impact factors $0.36(\mathrm{RG})$ and 0.642 (JCR) respectively. The greatest number of publications $(n=36)$ over the over the period examined were in the; Journal of Physical Therapy Science, which had an Impact Factor of 0.392 (JCR). Sixty-nine journals had only one publication from the authors affiliated with the Physical Therapy universities in SA, and their journal metrics ranged from 0.11 (Citescore) ${ }^{18}$ to 4.703 (JCR). Thirty-seven journals had more than one publication, ranging between two and 15. Moreover, the Journal of Physical Therapy Science has the largest number of publications, so it was considered the core journal in this study. 


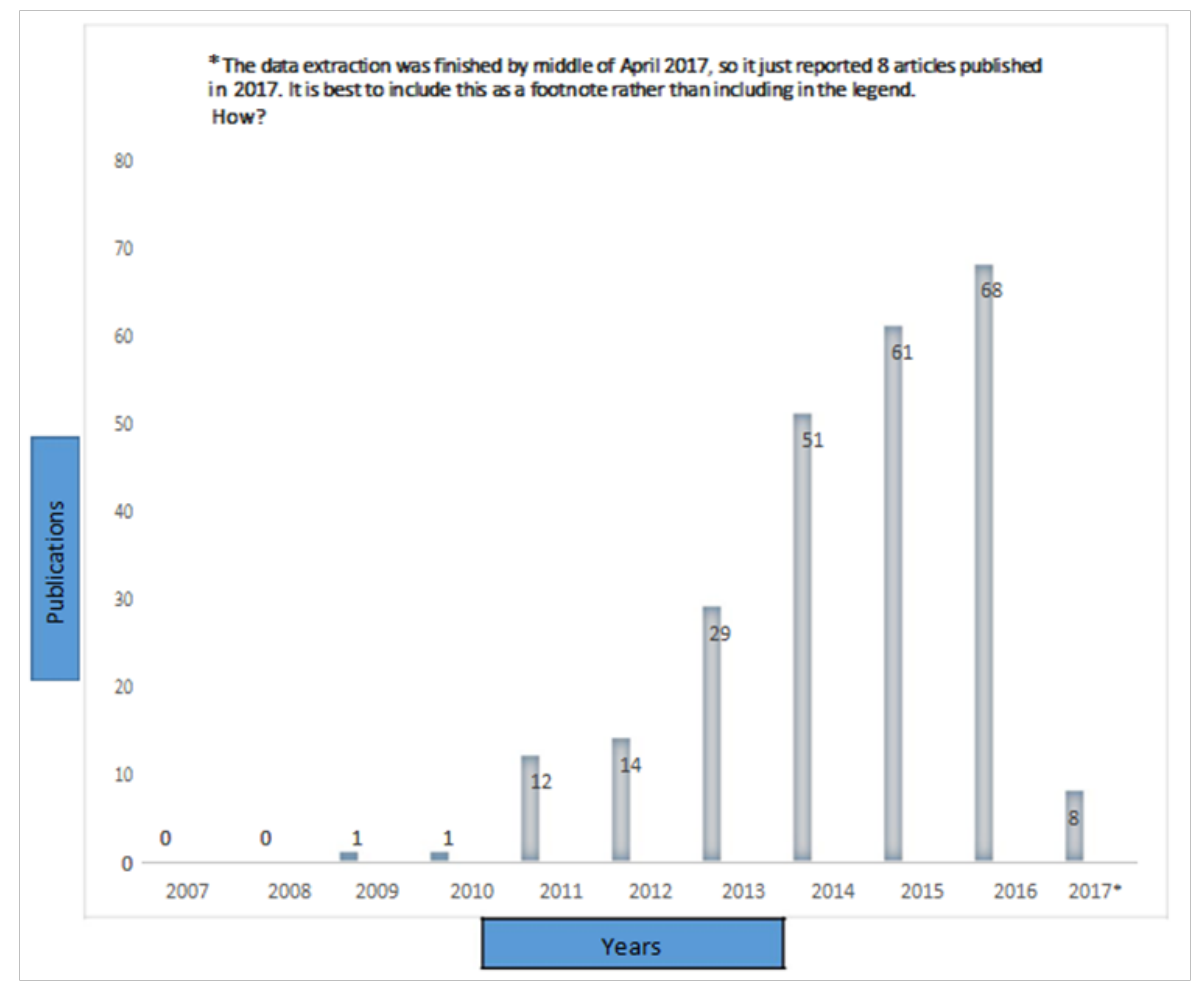

Figure 2 Publications of Saudi Arabian's physical therapy academic staff members from 2007 to April 2017.

\section{Discussion}

To date, no previously published content-analysis studies have analysed the publications generated by Physical Therapy academic members in the 14 Saudi Arabian universities offering a Physical Therapy programme. This is the first bibliometric and content-analysis study concerning this target and it provides insight into the emergence of research to support the development of the Physical Therapy profession in a major country in the Gulf region. Four international databases and detailed hand searching were used to locate the publically available articles on which this analysis was conducted.

The number of publications has increased from zero in 2007 to an accumulated total of 1127 by early 2017, with 245 of these meeting the study inclusion criteria. The steady rise in the annual outputs, particularly over the last 4-5 years indicates a positive trend and it can be speculated that this trend will continue in the foreseeable future. The Rehabilitation Sciences programme at King Saud University, the first University to offer Physical Therapy Programmes in SA, accounted for $92(37.5 \%)$ of the outputs (Alghadir, Zafar, Iqbal and Anwer, 2015; "College of Applied Medical Sciences"). In contrast the University of Otago School of Physiotherapy, which was established in 1913 but joined the university in 1996 produced 405 peer-reviewed papers over the same period, 2007 to 2017 ("Scopus.405 document results").

The publications are in a wide range of peer-reviewed journals with varying strengths of bibliometric properties. Fewer than 10 papers were published in what may be considered "core" Physical Therapy/Physiotherapy journals such as: Journal of Physical Therapy Science, JOSPT, Physiotherapy, and Physiotherapy Theory and Practice, all of which reflect the Physical Therapy profession. The reason for the low number is not clear. It may reflect the nature of the research being conducted or the researchers desire to share their work and increase their academic profile in specific areas or journals of interest to Gulf readers. Alternatively, it might be speculated that there is a research culture of publishing, irrespective of the journal title. This may be in response to the "acknowledgements and rewards system" within the universities or that certain journals are more associated with the intended target audience. The emergence of a research culture is illustrated by the practices at $\mathrm{KSU}$, an institution that is interested in improving its research output. KSU encourages research by providing financial grants to those who wish to publish; the rewards might reach up to $\$ 1000$, in order to motivate research. ${ }^{19,20}$ While the volume of papers published is a key indicator of research activity, it is also necessary to look at the "quality" of the journals the research is published in. In the growing area of journal bibliometrics, statistics describe various aspects of how papers in a given journal are cited by other researchers, and these measures are now becoming the international currency of the perceived "quality" of research published in a given journal. Typically, they describe the "impact" or influence of the journal within its defined field. However, in the comments of Eugene Garfield, the father of research journal bibliometrics and author citation research, "impact simply reflects the ability of the journals and editors to attract the best papers available". ${ }^{21}$

A number of journal metrics exist with the Journal Impact Factor (JCR); (Citescore); and (RG) being the most well- known. As this metric is only available for the journals included in the specific database, this study also located other metrics (official websites such as journal webpages) to provide a comprehensive profile of the 107 journals identified. As each metric is specific, so comparisons cannot be made between metrics. The highest impact factor for all three metrics were; Sport Medicine that reported 5.579 (JCR); the World Journal of Hepatology 3.19 (Citescore); and International Journal of Health Policy and Management $1.36(\mathrm{RG})$. 
Overall, most of the 107 chosen journals had solid impact factors based on the different metrics different journal metrics thus showing some quality differences between publications. On the other hand, understanding of what a journal impact factor means might create some publishing competition and that will help to improve the quality of the research generated and the journal targeted for publication.

Saudi Arabia is one of the fastest developing economies in the world. The Saudi Vision 2030 strategy includes a comprehensive educational and financial plan to drive the nation forward. ${ }^{14}$ Central to this vision is the need to develop a strong research ethos within the university sector. Notwithstanding the goal of this recent forwardthinking document, there has been a systematic increase in the number of peer-reviewed publications from the 14 Physical Therapy programmes in the Kingdom of Saudi Arabia.

On 25 April 2016, Deputy Crown Prince Mohammad bin Salman Al Saud released a vision of the future of the nation, entitled Saudi Vision 2030. This 2030 vision details government funding of education, as well as classifying the wide-ranging guidelines, strategies, purposes, and goals of the Kingdom. Moreover, ministries, organisations, and government units have gone through a reform process to guide them to the requirements of this stage. This could help them to achieve their responsibilities and develop their capabilities. In the end, the main goal of this vision is the enhancement of the level and value of facilities delivered to students, in order to achieve a more productive and efficient future. ${ }^{14}$ This reflects the growing awareness and expectations of university staff to be engaged in research and to publish the results of their findings. With the Physical Therapy profession being a relatively new academic discipline in SA, it is expected that it would take some time to establish and for staff to gain research training and skills. The growth in research has been fuelled in part by the increasing availability of government funding support and an increase in the number of scholarships to allow students to undertake higher education degree and research training in Physical Therapy/Physiotherapy in foreign countries.

According to the findings from this study, there has been a steady increase in research outputs over the period analysed. This reflects the growth of the Physical Therapy profession as an academic disciple in Saudi Arabia. However, it is too early to say whether this increase is due to the Saudi Vision 2030 or due to the academic goals of the departments. However it does indicate that the research in Physical Therapy in SA is moving forward and providing a solid foundation for contributing to clinical practice in Saudi Arabia and internationally.

\section{Strengths and limitations}

\section{Strengths of this study}

This is the first study of its kind to deliver a detailed analysis about Physical Therapy departments' publications. This study used four different search engines to collect publication data, which resulted in a comprehensive collection of publications. Also, the study used three different databases for determine journal metrics. This study was rigorous in its method and provided a variety of data analysis techniques.

\section{Limitations of this study}

Due to its scope, the study did not extract and identity the study designs and did not aim to analyse the quality of the individual studies and/or the level of evidence. The addition of this information may have been enlightening about the research outputs originating from SA. As this study excluded conference proceedings and abstracts it on gives a limited profile of the research being conducted.

Another limitation of this study was that it only considered articles published in English. Although English is accepted as the international language for research outputs, there may have been a parallel output of papers in Arabic - the official language of Saudi Arabia. The study did not attempt to quantify the study designs used to gauge if the outputs represented original research or reviews. Nor did it attempt to quantify whether the primary or corresponding author were associated with a particular Physical Therapy programme indicating whether they were the primary persons conducting the research. Although the search, article inclusion and data extraction followed a systematic and predetermined criteria this was conducted by the researcher. Thus the potential for bias must be considered a limitation of the study. It would have been informative to quantify the topics and/or areas of the research. This would have been a useful exercise but would require multiple assessors to ensure the quality of the exercise and this was not possible within the context of this study.

\section{Directions for future research}

This study has highlighted the need for further research in order to better understand the research productivity associated with the Physical Therapy programmes. For instance, it would be of interest to survey staff members to determine if research is an expected part of their academic workload and whether they have sufficient time and resources to conduct high-quality research. The replication of this study in five years would provide an indication of whether the introduction of Saudi Vision 2030 has had any impact on the number of outputs and the quality of the journals they are published in.

Many question marks are around the journals that are often chosen by most of the Saudi Arabian universities ${ }^{22}$ to publish in. Some examples of these questions are the following: a) Is it because of difficulty in submitting? b) Is it that researchers cannot find relevant physical therapy journals? c) Is there careless from author to just submit anywhere? d) Is there a problem with the quality of publications' topics and areas of interest? These questions should be answered to help to improve the Physical Therapy research and education in Kingdom of Saudi Arabia (Appendix 3)..$^{23-26}$

\section{Conclusion}

This study presents systematic data with the purpose to develop our understanding into the research productivity of Physiotherapy staff members in Saudi Arabian universities. PRISMA flow trail was used to present the outcomes. This study involved the extraction of 245 articles via Scopus, ScienceDirect, Web of Science, and Google Scholar, with specified search techniques into affiliation of Saudi universities, and names of Physical Therapy departments according to official websites.. The research was published in 107 journals of varying bibliometric quality. It is expected that research outputs will continue to increase due the growing focus on research within SA university sector.

\section{Acknowledgment}

I would like to say a huge thank you to Thelma Fisher for your input with this project. She has encouragement before staring the course of research project. 


\section{Conflicts of interest}

The authors declare no conflict of interest.

\section{References}

1. Alghadir A, Zafar H, Iqbal Z, et al. Physical therapy education in Saudi Arabia. Journal of Physical Therapy Science. 2015;27: 1621-1623.

2. http://cams.ksu.edu.sa/en

3. Al Maghraby M, Alshami A. Learning style and teaching method preferences of Saudi students of physical therapy. Journal of Family \& Community Medicine. 2013;20(3):192-197.

4. Gandevia B. Research in physiotherapy. Australian Journal of Physiotherapy. 1956;2(1):5-19.

5. Gibson B, Martin D. Qualitative research and evidence-based physiotherapy practice. Physiotherapy. 2003;89:350-358.

6. Bridges $\mathrm{P}$, Bierema L, Valentine $\mathrm{T}$. The propensity to adopt evidencebased practice among physical therapists. BMC Health Services Research. 2007;7:103.

7. Gorgon R, Basco S, Manuel T. Teaching evidence based practice in physical therapy in a developing country: a national survey of Philippine schools. BMC Medical Education. 2013;13:154

8. Larin H, Wessel J, Al-Shamlan A. Reflections of physiotherapy students in the United Arab Emirates during their clinical placements: A qualitative study. BMC Medical Education. 2005;5:3.

9. Bialocerkowski A, Johnson A, Allan T, et al. Development of physiotherapy inherent requirement statements-an Australian experience. BMC Medical Education. 2013;13:54

10. Sole G. University of Otago: towards specialisation with a masters in physiotherapy, endorsed in sports physiotherapy (continuing professional development series). British Journal of Sports Medicine. 2017;51:481-482.

11. http://www.lexology.com/library/detail.aspx?g=ddc8ee5b-6fae-4e7aabf7-a16c1c7ddd $4 b$

12. Coronado R, Wurtzel W, Simon C, et al. Content and bibliometric analysis of articles published in the journal of orthopaedic \& Sports physical therapy. Journal of Orthopaedic \& Sports Physical Therapy. 2011;41(12):920-931.

13. Milidonis M, Godges J, Jensen G. Nature of clinical practice for specialists in orthopaedic physical therapy. Journal of Orthopaedic \& Sports Physical Therapy. 1999;29:240-247.

14. http://vision2030.gov.sa/en/ntp

15. Moher D, Liberati A, Tetzlaff J, et al. Preferred reporting items for systematic reviews and meta-analyses: the PRISMA statement. PLoS Medicine. 2009;6(7):1-6.
16. https://images.webofknowledge.com/images/help/WOS/hs_citation applications.html

17. Yu M-C, Wu Y-CJ, Alhalabi W, et al. ResearchGate: An effective altmetric indicator for active researchers?. Computers in Human Behavior. 2016;55:1001-1006.

18. https://www.elsevier.com/editors-update/story/journal-metrics/ citescore-a-new-metric-to-help-you-choose-the-right-journal

19. https://www.journals.elsevier.com/journal-of-king-saud-universityscience/

20. https://hesr.ksu.edu.sa/en/node/395

21. Garfield E. How can impact factors be improved?. BMJ. 1996;313:411413.

22. http://kr.moe.gov.sa/ar/eservices/Pages/ksa_gov_universites.aspx.

23. https://www.elsevier.com/solutions/scopus.

24. Fell D, Burnham J, Buchanan M, et al. Mapping the core journals of the physical therapy literature. Journal of the Medical Library Association. 2011;99(3):202-207.

25. https://scholar.google.com/intl/en/scholar/about.html

26. https://www.physioboard.org.nz/sites/default/files/Recertification $\% 20$ Guidelines\%20\%202016\%20\%284th\%20ed\%29.pdf

27. https://www.topuniversities.com/universities/university-otago

28. Schreiber J, Stern P. A review of the literature on evidence-based practice in physical therapy. Internet Journal of Allied Health Sciences and Practice. 2005;3:9.

29. https://www.scopus.com/results/results.uri?sort=plf

30. Sharma M, Sarin A, Gupta P, et al. Journal impact factor: its use significance and limitations. World Journal of Nuclear Medicine. 2014;13(2):146

31. Steiner A, Ryser L, Huber E, et al. Use of the ICF model as a clinical problem-solving tool in physical therapy and rehabilitation medicine. Physical therapy. 2002;82:1098-1107.

32. http://www.kau.edu.sa/Pages-University-Mission.aspx

33. Veras M, Kairy D, Paquet N. What Is evidence-based physiotherapy? Physiotherapy Canada. 2016;68(2):95-96.

34. http://clarivate.com/?product=web-of-science

35. Westerdahl E. Physical therapy research in professional clinical practice. Journal of Novel Physiotherapies. 2013;3:1-5.

36. https://www.elsevier.com/solutions/sciencedirect 